\title{
АНАЛИЗ УСТОЙЧИВОСТИ ПОЛИМЕРНЫХ МАТЕРИАЛОВ В ЭКСТРЕМАЛЬНЫХ УСЛОВИЯХ МЕТОДОМ ЦВЕТОМЕТРИИ
}

\author{
В. Б. Иванов, Е. В. Солина, А. В. Саморядов
}

\begin{abstract}
ВИКТОР БОРИСОВИЧ ИВАНОВ - д.х.н., профессор, главный научный сотрудник, заведуюший лабораторией фотохимии полимеров ФГБУН федерального исследовательского иентра химической физики uм. H.H. Семенова PAH. E-mail: ivb@chph.ras.ru.
\end{abstract}

ЕЛЕНА ВИКТОРОВНА СОЛИНА - к.т.н., стариий научный сотрудник лаборатории фотохимии полимеров. Федеральное государственное бюджетное учреждение науки Федеральный исследовательский иентр химической физики им. Н.Н. Семенова Российской академии наук. E-mail: elenasolina@gmail.com.

АЛЕКСАНДР ВЛАДИМИРОВИЧ САМОРЯДОВ - д.т.н., главный научный сотрудник ФГБУНмежведомственного иентра аналитических исследований в области физики, химии и биологии при Президиуе РАН. E-mail:a2612sam@yandex.ru.

119991, ГСП-1, Москва, ул. Косыгина, 4. Федеральное государственное бюджетное учреждение науки Федеральный исследовательский иентр химической физики им. Н.Н. Семенова Российской академии наук.

117342, Москва, ул. Профсоюзная, д. 65, стр. 6. Федеральное государственное бюджетное учреждение науки Межведомственный центр аналитических исследований в области физики, химии и биологии при Президиуме Российской академии наук.

Рассмотрены преимущества и недостатки метода количественной цветометрии для оценки устойчивости полимерных и композиционных материалов на основе поливинилхлорида и полифениленсульфида при воздействии высоких температур и света. Проанализированы кинетические закономерности и особенности изменения иветового различия и иветовых характеристик при термо-, фото- и фототермической деструкиии. Оиенены энергии активации процессов. Показана перспективность кинетического подхода для оценки характеристик деструкиии и прогнозирования устойчивости.

Ключевые слова: поливинилхлорид, полифенленсульфид, термодеструкция, фотодеструкция, фотохромизм, цветометрия. 


\title{
ANALYSIS OF THE POLYMER MATERIAL STABILITY UNDER EXTREMAL CONDITIONS BY USING COLORIMETRY METHOD
}

\author{
V. B. Ivanov ${ }^{1}$ E. V. Solina ${ }^{1}$, A. V. Samoryadov ${ }^{2}$ \\ 14 Kosygin Street, Moscow, 119991, Russia; Semenov Federal Research Center for Chemical Physics RAS. \\ ${ }^{2} 65$ Profsoyuznaya Street, Moscow, 117342, Russia; Interdepartmental Center for Analytical Research in Physics, \\ Chemistry, and Biology, Presidium RAS.
}

We considered the assets and disadvantages of the colorimetric method for an estimation of the stability of polymers and polymeric materials based on polyvinyl chloride and polyphenylene sulfide under the action of high temperature and light. The kinetic regularities and peculiarities of the color difference and characteristics changes during thermo-, photo- and photothermodegradation were analyzed. It was estimated the activation energies of processes. The outlook of the kinetic approach for the estimation of degradation characteristics and stability forecasting was shown.

Keywords: colorimetry, photodegradation, polyvinyl chloride, polyphenylene sulfide, reversible color change, thermodegradation.

\section{Введение}

Количественную цветометрию широко используют для объективной сравнительной оценки различных материалов и изделий, в том числе изделий из пластических масс, лаков и красок, а также тканей. Эти методики применяют и для количественной оценки изменения внешнего вида материала при различных физико-химических воздействиях, включая и действие высоких и низких температур, света, агрессивных газов, воды (влажности), а также сочетание двух или нескольких этих факторов. В многочисленных научно-технических публикациях цветометрию используют и с целью сравнительной оценки стабильности материалов и эффективности новых стабилизирующих систем.

Потенциально метод цветометрии может применен практически ко всем полимерам и композиционным материалам, поскольку все они в той или иной степени окрашиваются или меняют свою окраску под действием внешних факторов, особенно высоких температур и света. Однако наиболее перспективным представляется использование этого метода для полимеров, в которых при деструкции происходит образование полисопряженных структур (ПСС). Высокие коэффициенты экстинкции таких структур в видимой области спектра позволяют изучать процессы на начальных стадиях, когда их концентрации малы, а основные физико-химические характеристики материа- ла еще не изменились или сохраняются на приемлемом для эксплуатации уровне. В то же время, метод позволяет прямым образом анализировать непосредственно реакции с участием макромолекул, то есть диагностировать одну из основных потенциальных причин изменения свойств материала.

Образование ПСС и связанное с этим изменение окраски наиболее ярко проявляется в процесcax термо- и фотодеструкции поливинилхлорида (ПВХ) [1-3] и полифениленсульфида [4, 5]. Поэтому в данной работе с использованием опубликованных нами ранее [6-10] и новых экспериментальных данных рассмотрены общие закономерности и особенности деструкции именно этих полимеров. Дополнительный интерес к изученным объектам обусловлен широким использованием материалов на основе этих полимеров в электротехнической, электронной, аэрокосмической и других отраслях промышленности.

Основная цель работы - продемонстрировать преимущества и ограничения использования цветометрии при оценке и прогнозировании устойчивости полимерных и композиционных материалов.

\section{1. Методологический подход, используемый при анализе устойчивости материалов методом иветометрии}

В международной системе CIELAB-76 [11] цвет образца характеризуется точкой в трехмер- 
ном пространстве координат L*, $\mathrm{a}^{*}, \mathrm{~b}^{*}$, причем L* определяет яркость (светлоту), параметр а*, в зависимости от знака, интенсивность красного $(+)$ и зеленого (-) цвета, a b* - желтого $(+)$ и синего (-) цвета. В качестве основной характеристики изменения цвета используют величину цветового различия $\Delta \mathrm{E}$, определяемого по формуле (1):

$$
\Delta \mathrm{E}=\left[\left(\Delta \mathrm{L}^{*}\right)^{2}+\left(\Delta \mathrm{a}^{*}\right)^{2}+\left(\Delta \mathrm{b}^{*}\right)^{2}\right]^{1 / 2}
$$

где $\Delta L^{*}=L^{*}{ }_{\mathrm{i}}-L^{*}{ }_{0}, \Delta a^{*}=a_{\mathrm{i}}-a_{0}, \Delta b^{*}=b_{\mathrm{i}}^{*}-b_{0}^{*}$, причем индекс 0 в общем случае относится к образцу до испытаний, а индекс $\mathrm{i}$ - к образцу после определенного периода испытаний. Величины $L^{*}, a^{*}$, и $b^{*}$ определяются непосредственно в результате измерений по стандартной процедуре обработки спектров отражения с помощью программного обеспечения спектроколориметра. В некоторых случаях оказывается более целесообразным использовать в качестве основной характеристики величину $\Delta \mathrm{b}^{*}$. Возможность этого обусловлена тем, что на начальных стадиях образуются ПСС с относительно короткой цепью сопряжения, поглощающие преимущественно в синей области спектра. Вследствие этого именно величина $b^{*}$ является мерой концентрации таких структур в поверхностном слое.

Отметим, что цветометрические характеристики являются хотя и условно, но строго определяемыми из спектров отражения параметрами, преимущество использования которых обусловлено возможностью в количественной форме представить наблюдаемые визуально изменения материала.

Цветометрию обычно используют для оценки качества или изменения характеристик материала на основании критериев допустимого цветового различия или допустимых изменений цветовых координат.

Развиваемые в последнее время подходы включают анализ кинетических закономерностей изменения $\Delta \mathrm{E}$ и цветовых координат [6-10]. Определяемые кинетические параметры и зависимости кинетики от условий, в которых протекает деструкция, используются для выявления роли основных внешних факторов и компонентов материала в процессах изменения цветовых характеристик, что позволяет оценить их влияние на образование ПСС и других продуктов деструкции. Для более объективной оценки полученные данные сопоставляются с результатами исследования этих же или аналогичных материалов другими методами, в том числе ДСК, ТГА, ТМА, ИК-спектроскопии и методами физико-механического анализа. Установленные закономерности и определяемые кинетические параметры представляют собой научную ос- нову для прогнозирования устойчивости материалов и изделий при хранении и эксплуатации, включая и эксплуатацию в экстремальных условиях.

\section{2. Деструкичи при высоких температурах}

Ранее декларировалось [12], что дегидрохлорирование пластифицированного ПВХ, приводящее к окрашиванию материала, происходит только при температурах выше $120^{\circ} \mathrm{C}$.

Более детальный анализ позволил установить, что окрашивание возникает и при более низкой температуре $100-110{ }^{\circ} \mathrm{C}[6,7]$. Показано также, что регистрируемые изменения цветового различия $\Delta \mathrm{E}$ определяются лавным образом увеличением $\Delta \mathrm{b}^{*}$, характеризующим возрастание степени желтизны образцов. Это подтверждает связь изменения окраски с образованием ПСС, и, следовательно, кинетические закономерности изменения цвета отражают закономерности химического процесса дедидрохлорирования ПВХ.

Как показано на рис. 1, и начальная скорость накопления ПСС, и, что более важно, их квазистационарная концентрация тем меньше, чем ниже температура. Зависимости, представленные на рис. 1, удовлетворительно описываются кинетическим уравнением реакции 1-го порядка (2):

$$
\Delta E=\Delta E_{\infty}[1-\exp (-k t)]
$$

где $\Delta E_{\infty}-$ стационарное (предельное) значение $\Delta E$, a $k$ - константа скорости процесса достижения этого значения, причем от температуры испытания зависит и $k$, и величина $\Delta E_{\infty}$.

Рассчитанные по данным рис. 1 и зависимости параметров изменения $\Delta \mathrm{b}^{*}$ от температуры значения энергии активации $\mathrm{E}_{\mathrm{a}}$ совпадают и составляют 70-71 кДж/моль. Полученное таким образом значение энергии активации находится в полном соответствии с величиной $\mathrm{E}_{\mathrm{a}}=74$ кДж/моль, определяемой при анализе изменения модуля при изотермическом старении пластифицированного ПВХ при $100-130{ }^{\circ} \mathrm{C}[13]$.

Выход содержания ПСС на квазистационарный уровень при длительном нагреве на воздухе обусловлен конкуренцией процессов образования ПСС и их расходования в результате термоокисления. В соответствии с этой гипотезой скачкообразное увеличение температуры приводит к резкому увеличению скорости накопления ПСС и постепенному переходу на новый, более высокий квазистационарный уровень (рис. 2). Дополнительным аргументом является уменьшение $b^{*}$ для предварительно прогретых при повышенной температуре образцов при их выдерживании при более низкой 


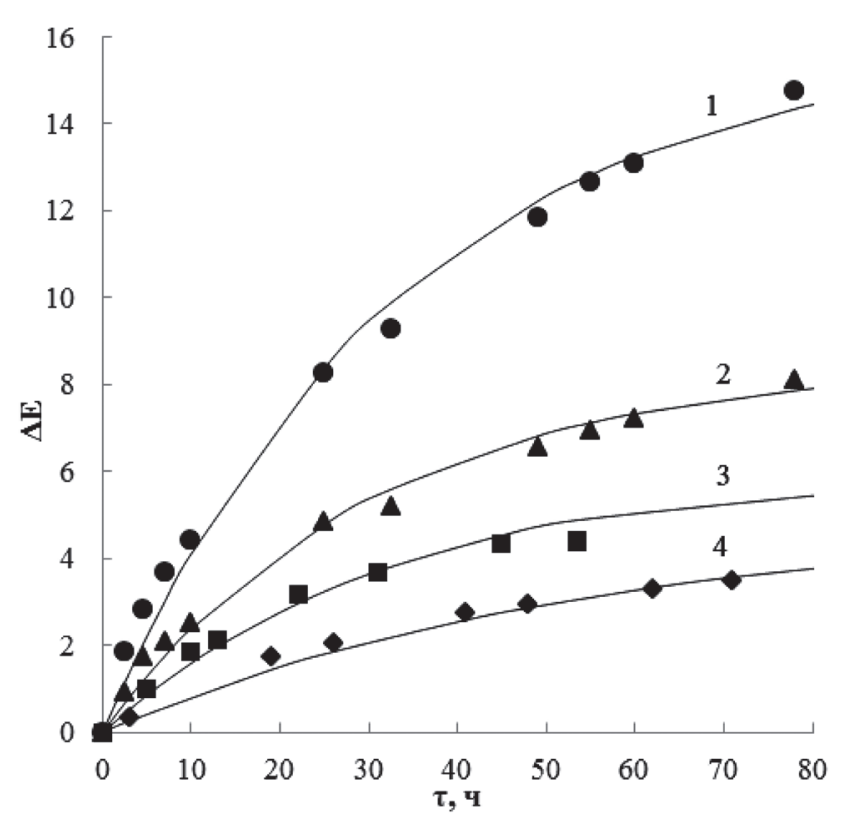

Рис. 1. Увеличение цветового различия $\Delta E$ в процессе термического старения пластифицированного ПВХ при температурах $100-130{ }^{\circ} \mathrm{C}$

Точки - экспериментальные данные, кривые - расчет по уравнению (1) при $\Delta E_{\infty}$ (в скобках $\left.-k, \psi^{-1}\right) 3,9(0,029)$, $4,9(0,046), 8,3(0,035)$ u $14,4(0,036)$

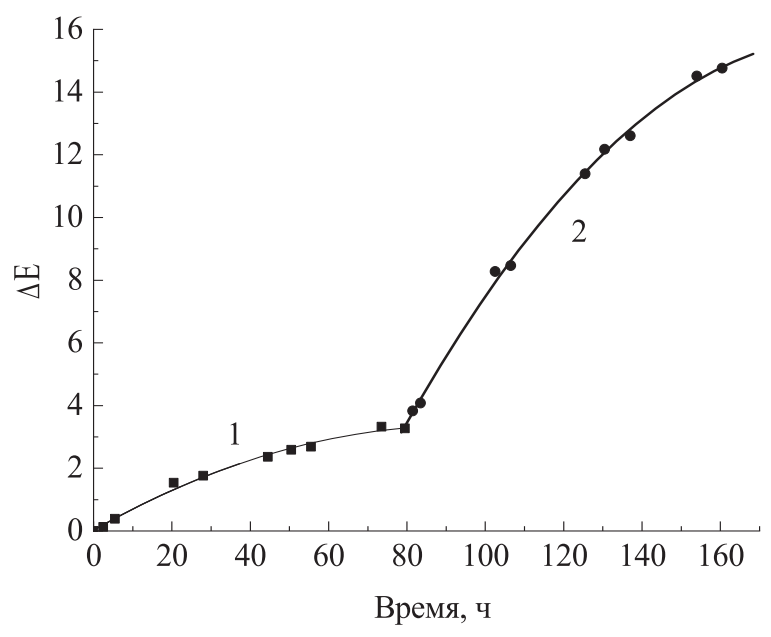

Рис. 2. Постепенное приближение величины $\Delta E$ к квазистационарному значению, характерному для температуры 130 $\mathrm{C}$, при последовательном нагревании пластифицированного ПВХ при 100 (1) и $130{ }^{\circ} \mathrm{C}(2)$

температуре (рис. 3). Интересно, что в этом случае формально определяемая энергия активации процесса является отрицательной величиной, так как его скорость растет при уменьшении температуры. Естественно предположить, что это явление также обусловлено конкуренцией процессов обра- зования и расходования ПСС. В данных условиях при понижении температуры более резко снижается скорость дегирохлорирования ПВХ, так как этот процесс характеризуется более высоким значением $\mathrm{E}_{\mathrm{a}}$, чем окислении ПСС.

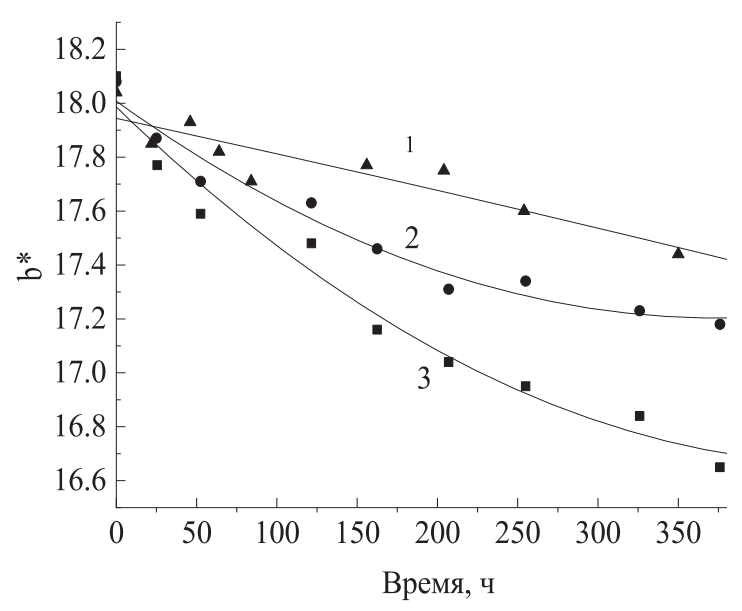

Рис. 3. Уменьшение желтизны образцов пластифицированного ПВХ, предварительно термически состаренных при $130{ }^{\circ} \mathrm{C}$ в течение 43 ч, при выдерживании при температуре 80 (1), 70 (2) или $60{ }^{\circ} \mathrm{C}(3)$

При нагревании композиционных материалов на основе ПФС также наблюдается окрашивание, первоначально в светло-бежевый, а при более продолжительном нагревании - и в более темный цвет.

Для стеклонаполненного композита, не содержащего модификаторов ударной вязкости, изменение $\Delta$ Е после первоначальной очень быстрой стадии («скачка») длительное время происходит с практически постоянной скоростью, которая естественным образом увеличивается с ростом температуры. Зависимость стационарной скорости от температуры в диапазоне $90-130{ }^{\circ} \mathrm{C}$ удовлетворительно описывается уравнением Аррениуса (рис. 4). Энергия активации деструкции находится в диапазоне 110-120 кДж/моль. Особенность начальной стадии (скачок $\Delta \mathrm{E}$, который также растет с увеличением температуры) обусловлена, по-видимому, быстрым образованием ПСС с большой длиной сопряжения из предшественников с малой длиной цепи сопряжения, которые образовались при получении композита и изготовлении образцов, осуществляемых при высоких температурах.

Форма кинетических кривых изменения $\Delta \mathrm{E}$ для композита, содержащего для повышения ударной вязкости сополимер этилена и глицидилметакрилата (4-20 масс.\%) зависит от температуры (рис. 5). При невысоких темпера- 


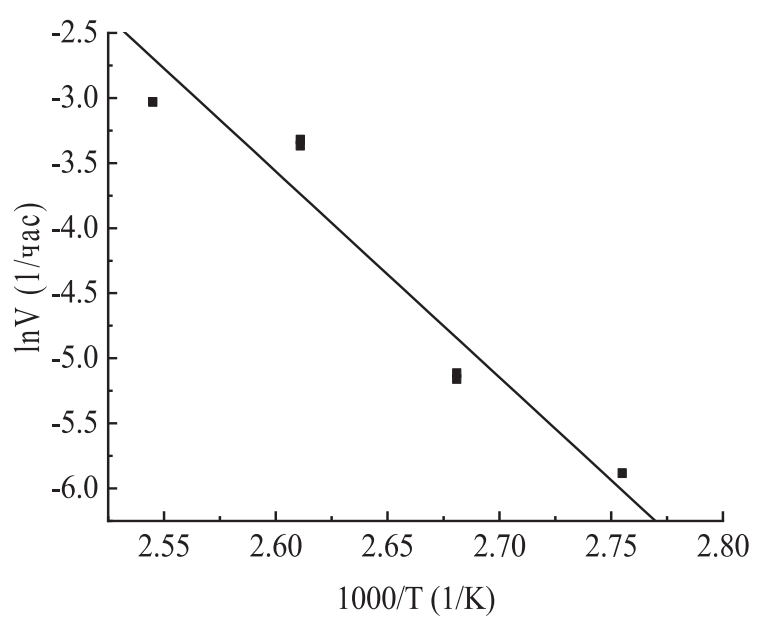

Рис. 4. Зависимость скорости увеличения $\Delta \mathrm{E}$ при термическом старении стеклонаполненного композита на основе ПФС от температуры в координатах уравнения Аррениуса

турах (100-110 $\left.{ }^{\circ} \mathrm{C}\right)$ процесс описывается линейной или близкой к ней функцией. Для повышенных температур, как и при термодеструкции ПВХ, характерна экспоненциальная зависимость (уравнение 2).

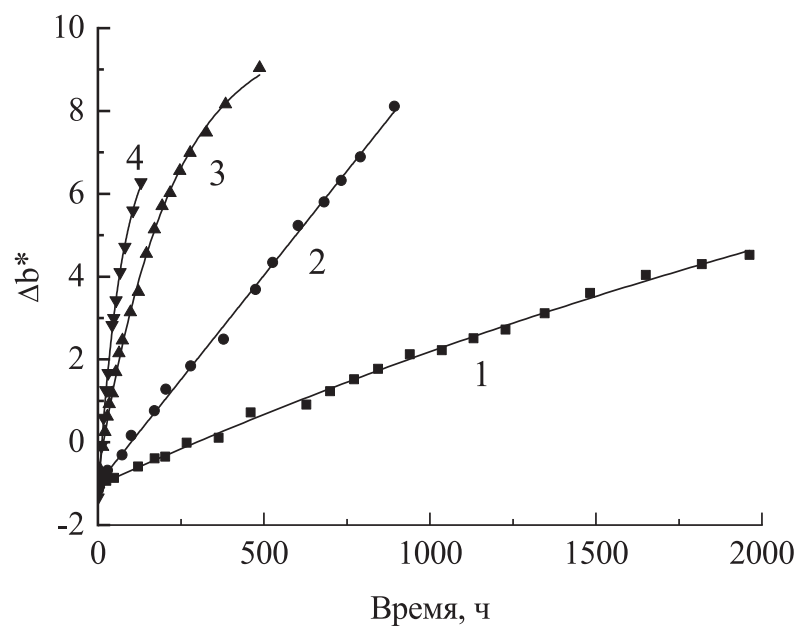

Рис. 5. Кинетические кривые накопления полисопряженных структур (по изменению $\left.\Delta \mathbf{b}^{*}\right)$ при термической деструкции ПФС, модифицированного сополимером этилена и глицидилметакрилата (10 масс.\%), при температуре 100 (1), 110 (2), 130 (3) или 140 C (4)

Начальная скорость деструкции увеличивается с ростом температуры в соответствии с уравнением Аррениуса. Определяемое таким образом значение энергии активации зависит от содержания модификатора и составляет 108-134 кДж/моль. Эта величина находится в хорошем соответствии с энергией активации композита ПФС/эластомер (119 \pm 17 кДж/моль), оцениваемой по изменению термически индуцированной люминесценции [14].

Таким образом, окрашивание ПВХ и ПФС протекает по аналогичным формально-кинетическим законам, что указывает на общий механизм явления, в основе которого образование ПСС. Некоторые особенности процессов связаны с влиянием компонентов на соотношение процессов образования ПСС и их расходования, главным образом в процессе окисления.

Определяемые экспериментально скорости и кинетические параметры деструкции позволяют прогнозировать устойчивость не только в условиях длительного хранения или эксплуатации в нормальных условиях, но при экстремально высоких температурах.

\section{3. Деструкичия при интенсивном световом воздействии}

При облучении ПВХ, как и при воздействии высоких температур, наблюдается образование ПСС и обусловленное этим окрашивание материала $[2,3]$. Для окрашенных и стабилизированных композиций характерно наличие индукционных периодов, величина которых определяется эффективностью стабилизаторов, а также устойчивостью и каталитической активностью пигментов и красителей (рис. 6) [8]. Скорость дегидрохлорирования после окончания индукционного периода, как и сама величина индукционного периода, зависит также от интенсивности и спектрального состава света [2]. Основной вклад, особенно

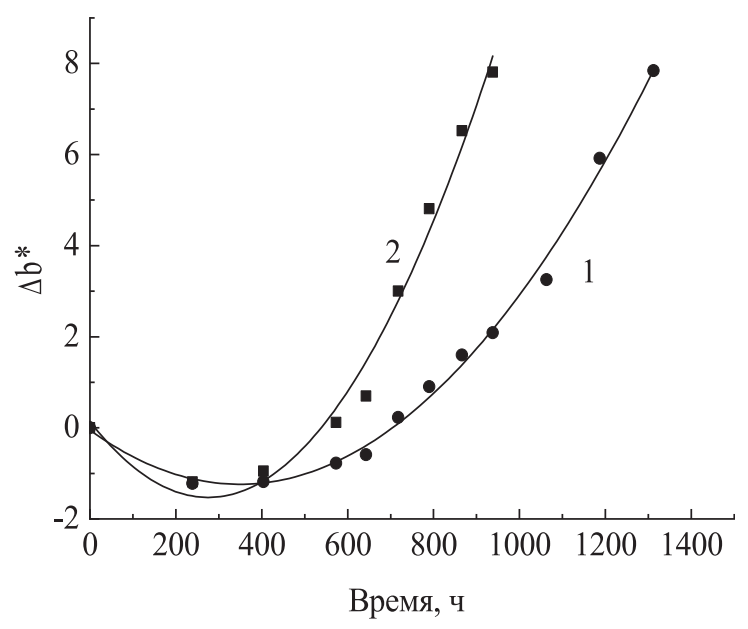

Рис. 6 Увеличение цветового различия $\Delta \mathrm{E}$ при облучении образца ПВХ белого цвета, содержащего диоксид титана с низкой (кривая 1) и высокой каталитической активностью (кривая 2) при температуре черной панели $50{ }^{\circ} \mathrm{C}$ 
на начальной стадии, вносит УФ-составляющая излучения, главным образом его коротковолновая часть $(\lambda \leq 320$ нм). Длинноволновый УФ-свет и видимое излучение ускоряют процесс дегидрохлорирования и индуцируют образование ПСС с большей длинно цепи сопряжения $[1,2]$, усиливая окраску. Однако одновременно происходит окисление ПСС, что в определенных условиях приводит ослаблению окраски, наиболее ярко выраженному при облучении образцов видимым светом после предварительного воздействия полного излучения или только его УФ-составляющей.

Кинетические закономерности образования ПСС при действии света на ПФС аналогичны закономерностями фотодеструкции ПВХ. Основной вклад в увеличение цветового различия $\Delta \mathrm{E}$ при облучении композита на основе ПФС вносит УФ-составлющая излучения, так как кинетические кривые при действии полного света (рис. 7, кривая 1) или только его УФ-части (рис. 7, кривая 2) практически совпадают. Длинноволновый ультрафиолет или видимое излучение также способны индуцировать окрашивание композита (рис. 7, кривые 3 и 4). Однако при таком воздействии процесс протекает с большой скоростью только после окончания индукционных периодов. Основной вклад в увеличение $\Delta \mathrm{E}$ вносит изменение $\mathrm{b}^{*}$, что свидетельствует о непосредственной связи окрашивания с образованием ПСС.

Постепенный выход величины $\Delta \mathrm{E}$ на квазистационарный уровень обусловлен протеканием, наряду с дегидрохлорированием, конкурирующего процесса расходования ПСС, также индуцированного светом. Наиболее четко эта вторая функ-

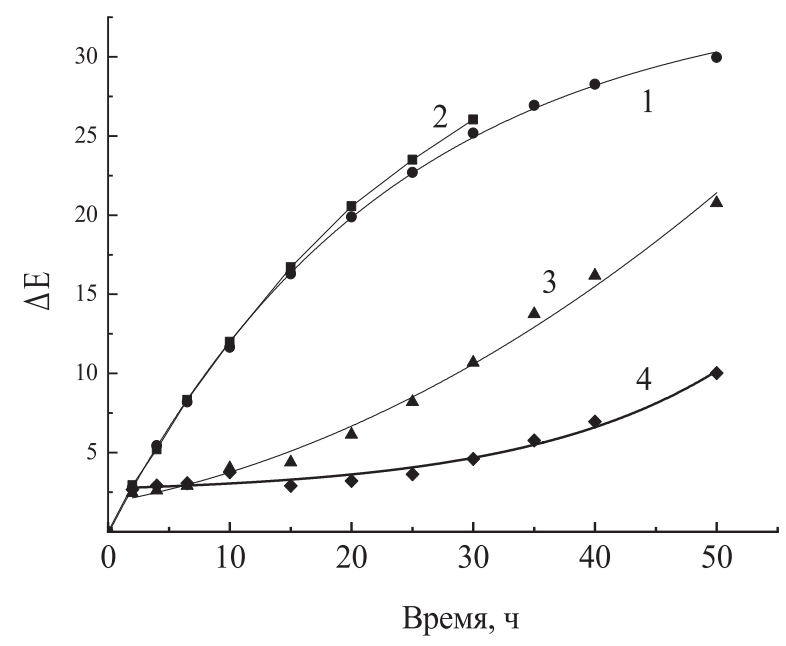

Рис. 7. Кинетические кривые изменения $\Delta \mathrm{E}$ при облучении композита на основе ПФС без дополнительных фильтров (1) и со светофильтрами, отрезающими коротковолновое излучение с $\lambda<280$ (2), $\lambda<380$ (3) или $\lambda<410$ нм (4) ция света проявляется в снижении интенсивности окраски при действии видимого света на образцы ПФС, предварительно облученные полным светом. Эффект воздействия видимого света наглядно и количественно можно оценить при анализе спектров отражения (рис. 8). После облучения полным светом коэффициент отражения R снижается во всей видимой области спектра (рис. 8, кривая 2). При последующем воздействии видимого света величина R увеличивается (образец становится светлее), причем возрастание $\mathrm{R}$ заметнее в длинноволновой области (рис. 8, кривая 3). Это свидетельствует о преимущественно снижении содержания ПСС с относительно большой длиной цепи сопряжения, что также связано с двойственной функцией света.

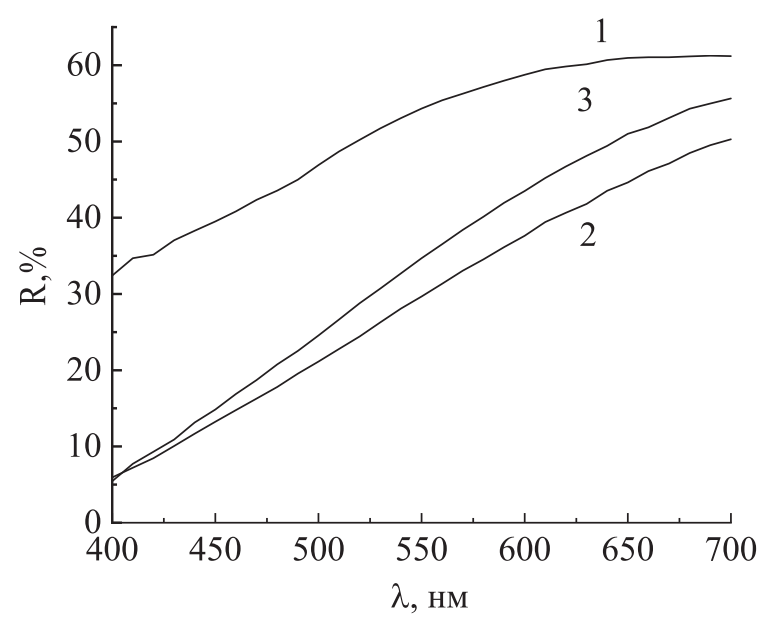

Рис. 8. Спектры отражения композита до облучения (1) и после облучения полным светом в течение 30 ч (2), а также дополнительного облучения светом с $\lambda>410$ нм в течение 20 ч

Основным каналом расходования ПСС при облучении видимым светом, как и при воздействии полного излучения, является их окисление. Об этом свидетельствует увеличение содержания кислородсодержащих групп, главным образом гидроксильных (-О-Н) и эфирных (-С-О-), регистрируемых в поверхностном слое методом НПВО.

При облучении ударопрочных композитов на основе смесей ПФС с сополимером этилена и глицидилметакрилата окисление затрагивает не только ПСС, но и эластомер, так как скорость образования эфирных групп в его присутствии резко возрастает и увеличивается с ростом содержания этого компонента. Обнаружено, что эластомер в композите окисляется и при облучении видимым светом, который ни сам сополимер, ни продукты его окисления и деструкции не по- 
глощают. Это означает, что окисление ПСС макромолекул ПФС способно инициировать окисление сополимера, то есть реализуется процесс сопряженного окисления. Можно полагать поэтому, что для таких материалов должны быть особенно эффективны не поглощающие свет антиоксиданты класса пространственно затрудненных аминов [15] и синергические смеси антиоксидантов с УФабсорберами [16].

Инициирующее действие коротковолновой части видимого света выражено сильнее, чем длинноволновой, поскольку величина индукционного периода изменения цветометрических характеристик тем больше, а скорость их накопления тем меньше, чем выше коротковолновая граница света (рис. 9, кривые 1 и 2). На кинетических кривых изменения $\mathrm{b}^{*}$ хорошо видны три участка: начальное уменьшение (стадия I), сохранение $b^{*}$ на практически постоянном уровне (стадия II) и увеличение $\mathrm{b}^{*}$ при длительном облучении (стадия III). Стадии II и III представляются вполне естественными, так как характерны для всех автокаталитических процессов. Необычной представляется стадия I, на которой фиксируется снижение $b^{*}$. Вероятная причина этого явления будет рассмотрена ниже.

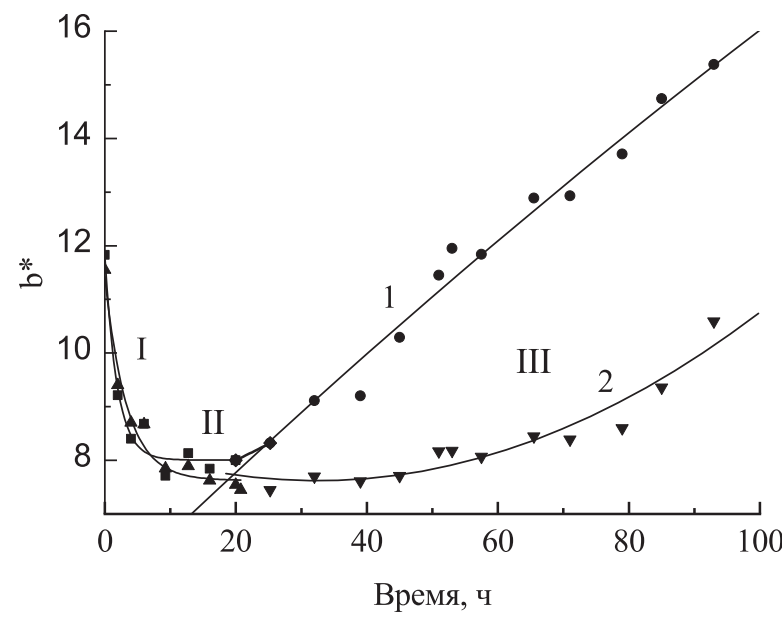

Рис. 9. Расходование и накопление полисопряженных структур при длительном облучении пластифицированного ПВХ видимым светом, выделяемым светофильтрами ЖС11, $\lambda \geq 410$ нм (1) или ЖС12, $\lambda \geq 440$ нм (2)

\section{4. Совместное действие высоких температур и света}

\section{1. Последовательное воздействие тепла и света}

Наиболее наглядно особенности фотодеструкции предварительно термически состарен- ных образцов ПФС проявляются при последующем их облучении видимым светом. Как видно на рис. 10, происходит увеличение коэффициента отражения $\mathrm{R}$ в коротковолновой области и менее выраженное уменьшение в длинноволновой (рис. 10, кривая 2). Это свидетельствует о преимущественном расходовании при облучении ПСС с небольшой длиной цепи сопряжения, что появляется также в более существенном изменении $\mathrm{b}^{*}$ по сравнению с другими цветовыми координатами. В целом же образец в процессе облучения становится светлее, и величина $\Delta \mathrm{E}$ по сравнению с термически состаренным образцом снижается. Этот результат позволяет понять природу резкого снижения $\mathrm{b}^{*}$, a, следовательно, и скачка $\Delta \mathrm{E}$ при облучении длинноволновым светом исходных образцов ПФС (рис. 7, кривые 3 и 4, а также рис. 9, стадия I). Объяснение наблюдаемых эффектов заключается в том, что ПФС исходных образцов также подвергался термическому воздействию на стадиях получения композита и изготовления образцов, осуществляемых при высоких температурах.

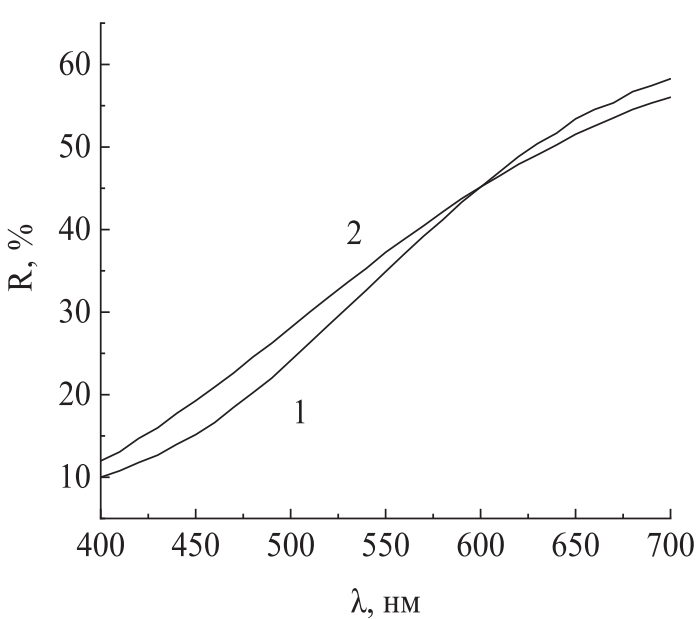

Рис. 10. Спектр отражения образца композита на основе ПФС после прогрева при $120{ }^{\circ} \mathrm{C}$ в течение 500 ч (1) и последующего облучения светом с $\lambda>$ 410 нм в течение 12 ч (2)

При другой последовательности внешних факторов, когда после предварительного облучения композит на основе ПФС подвергается воздействию высоких температур, наблюдается обратный эффект: резкое увеличение цветового различия $\Delta \mathrm{E}$. Однако и этот эффект наиболее четко наблюдается только после облучения видимым светом, и только в самом начале термодеструкции. Затем процесс осуществляется со скоростью, характерной для «обычной» термодеструкции при дан- 
ной температуре. По-видимому, явление обусловлено существенным снижением при облучении видимым светом содержания ПСС с относительно большой длиной цепи сопряжения, поглощающих в видимой области, без затрагивания коротких ПСС, поглощающих в УФ-области. Последующее термическое воздействие индуцирует превращение этих коротких ПСС в более длинные, что и вызывает увеличение поглощения в видимой области и интенсивности окраски.

\section{2. Одновременное действие тепла и света}

Как следует из рассмотренных выше примеров, окрашивание или изменение окраски под действием света происходит значительно быстрее, чем при нагревании даже при достаточно высоких температурах $\left(100-140{ }^{\circ} \mathrm{C}\right)$. Однако при совместном действии тепла и света вклад термических процессов в полимерных материалах может быть существенным. Поэтому энергия активации

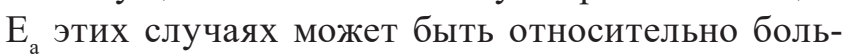
шой и во много раз превосходить значения этой характеристики для фотохимических реакций органических соединений в жидких и твердых растворах.

Образование ПСС требует существенной перестройки нескольких звеньев макромолекулы и их непосредственного окружения, поэтому именно для этого процесса даже при фотохимическом инициировании можно ожидать сильной зависимости от температуры. Действительно, как показано на рис. 11, при облучении ПВХ, содержащего дополнительно краситель и диоксид титана, величина индукционного периода измене-

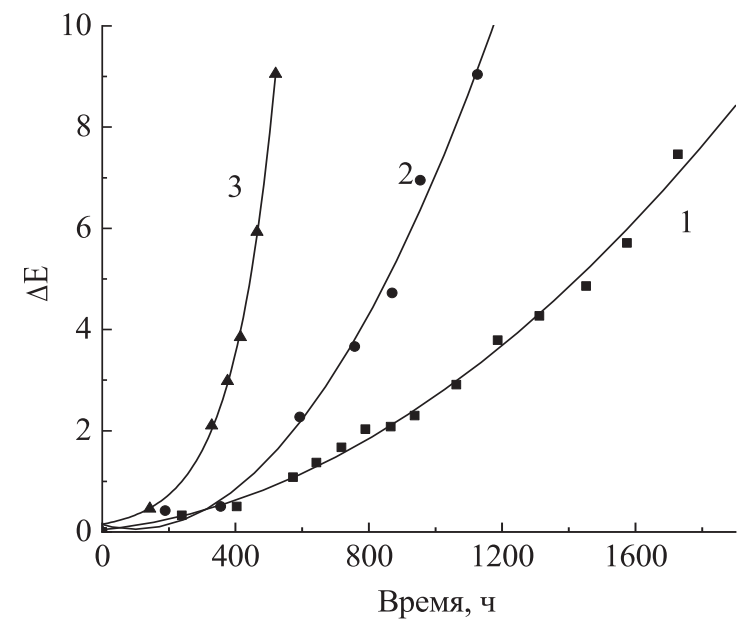

Рис. 11. Увеличение цветового различия при облучении ПВХ серо-голубого цвета при температуре черной панели 50 (1), 55 (2) или $60{ }^{\circ} \mathrm{C}(3)$ ния $\Delta \mathrm{E}$ с ростом температуры существенно уменьшается, а скорость процесса заметно увеличивается. В этом случае для оценки энергии активации целесообразно использовать подход, основанный на анализе зависимости от температуры времени достижения заданной степени конверсии (в нашем случае - изменения $\Delta \mathrm{E})[8,17,18]$.

На рис. 12 приведены зависимости величины $1 / \tau$ от обратной температуры $1 / \mathrm{T}$ в координатах уравнения Аррениуса (3):

$$
\ln (1 / \tau)=A \cdot \exp \left(-\mathrm{E}_{\mathrm{a}} / \mathrm{RT}\right)
$$

где $\tau$ - время облучения, ч, до достижения величины цветового различия 2 или 4; Т - температура черной панели, К; А - предэкспоненциальный множитель; R - универсальная газовая постоянная.

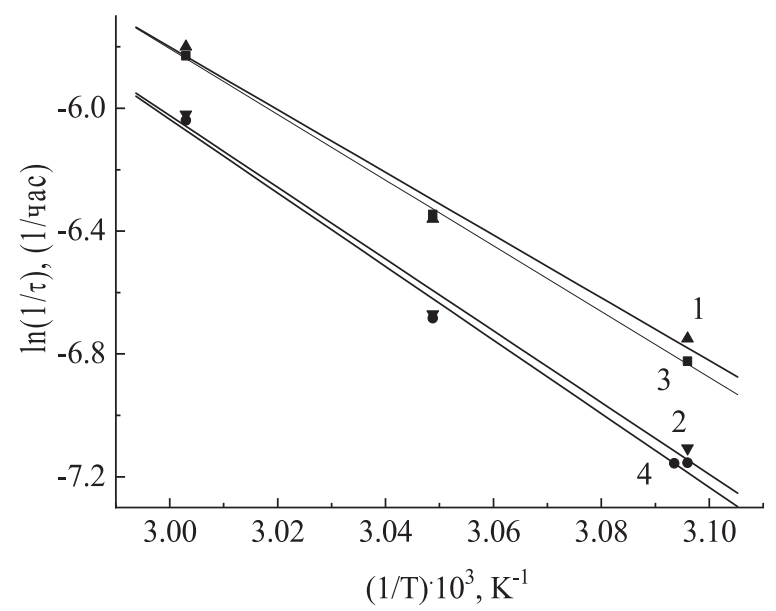

Рис. 12. Зависимости времени достижения величины цветового различия $(1,3)$ или изменения цветовой координаты $b^{*}(2,4)$ значений $2(1,2)$ или 4

$(3,4)$ от температуры в координатах уравнения

3 при облучении окрашенного ПВХ светом, моделирующим солнечное излучение

Энергия активации составляет 102 и 118 кДж/моль (для $\Delta \mathrm{E}=2$ и 4 , соответственно). Так как основной вклад в изменение $\Delta \mathrm{E}$ вносит увеличение $\mathrm{b}^{*}$, кинетика изменения цвета и в данном случае действительно отражает именно процесс образования ПСС при дегидрохлорировании ПВХ, а не превращение красителя. Отметим, что большие величины $\mathrm{E}_{\mathrm{a}}$, для инициируемых светом. процессов, как правило, обусловлены вкладом реакций, протекающих без непосредственного участия квантов света и имеющих относительно большую, характерную для термических процессов, энергию активации. К таким реакциям относится и дегидрохлорирование ПВХ. Поэтому и кинетика 
окрашивания ПВХ при облучении сильно зависит от температуры.

Скорость накопления ПСС при облучении композитов на основе ПФС также увеличивается с ростом температуры, но определяемая по уравнению (1) энергия активации существенно меньше и составляет лишь 34 кДж/моль (для $\Delta \mathrm{E}=2$ и 4). Вероятно, это обусловлено тем, что ПФС является аморфно-кристаллическим полимером и имеет более высокую температуру стеклования (90-105 ${ }^{\circ} \mathrm{C}$, в зависимости от микроструктуры полимера).

\section{Заключение}

Количественная цветометрия является неразрушающим и высокочувствительным метолом оценки устойчивости материалов на основе ПВХ и ПФС, позволяющим оценивать степень деструкции уже на самых ранних стадиях процесса.

Изменение цвета неокрашенных и светлоокрашенных композиций обусловлено образованием ПСС, поглощающих преимущественно в коротковолновой части видимой области, поэтому корректный анализ, наряду с изменением цветового различия $\Delta \mathrm{E}$, должен включать данные по кинетике изменения цветовой координаты $\mathrm{b}^{*}$, характеризующей окрашивание материала в желтый цвет, а также оценку изменения спектра отражения.

Ограничения использования цветометрии обусловлены двойственной функцией тепла и света, которые способны индуцировать не только образование ПСС, но и их расходование в результате окисления кислородом воздуха.

Конкуренция процессов образования и расходования ПСС ограничивает экспериментально определяемую скорость их накопления и квазистационарную концентрацию, что может приводить к снижению чувствительности метода.

При исследовании фотохимического и фототермического старения необходимо также учитывать возможный фотохромизм, проявляющийся в снижении интенсивности окраски при воздействии видимого света и ее восстановлении при нагревании или облучении УФ-светом.
Работа выполнена в соответствии с Госзаданием №0082-18-006, номер государственной регистраųии AAAA-A18-118020890097-1.

\section{Лumepamypa}

1. Gumargalieva K.Z., Ivanov V.B., Zaikov G.E., Moiseev Ju.V., Pokholok T.V. Polymer Degradation and Stability. 1996. V. 52. No 1. P. 73-79.

2. Zuravlev M.A., Ivanov V.B. European Polymer Journal. 1989. V. 25. No 4. P. 391-394.

3. Ivanov V.B., Zuravlev M.A. Polymer Photochemistry. 1986. V. 7. No 1. P. 55-64.

4. Das P.K., DesLauriers P.J., Fahey D.R. Polymer Degradation and Stability. 1995. V. 48. P. 11-23.

5. DesLauriers P.J.; Gelbel J.F.; Das P.K. Angewandte Makromolekulare Chemie. 1997. V. 247. P. 45-59.

6. Ivanov V.B., Solina E.V., Staroverova O.V., Popova E.I., Lazareva O.L., Belova O.A. Russian Journal of Physical Chemistry. B. 2017. V. 11. No 6. P. 978-984.

7. Ivanov, V.B., Popova E.I., Solina E.V. Polymer Science. B. 2017, V. 59. No 3. P. 348-351.

8. Ivanov V.B., Solina E.V. Polymer Science. D. 2019. V. 12. No 1. P. 100-104.

9. Ivanov V.B., Bitt V.V., Solina E.V., Samoryadov A.V. Polymers. 2019. 1579.

10. Ivanov V.B., Solina E.V., Samoryadov A.V. Polymer Science. D. 2020. V. 13. No 3. P. 353-357.

11. CIE 15.32004. CIE Technical report: Colorimetry: Third Ed. P. 17.

12. Linde E., Gedde U.W. Polymer Degradation and Stability. 2014. V. 101. No 1. P. 24-31.

13. Padmasiri K., Gamage, P. K., Farid A. S., Karunanayake L. Journal of Applied Polymer Science. 2009. V. 112. No 4. P. 2151-2165.

14. Steffen R., Meir M., Rekstad J., Röder B. Polymer. 2018. V. 136. P. 71-83.

15. Rozantsev E.G., Kagan E.S., Sholle V.D., Ivanov V.B., Smirnov V.A. ACS Symposium series. 1985. V. 280. P. 11-35.

16. Ivanov V.B., Rozenboim N.A., Angert L.G., Shlyapintokh V.Ja. Doklady Akademii Nauk SSSR. 1978. V. 241. No 3. P. 609-612.

17. Ivanov V.B., Zavodchikova A.A., Popova E.I., Lazareva O.L., Belova O.A., Kryuchkov I.A., Bykov E.V. Thermochim. Acta. 2014. V. 589. P. 70-75.

18. Vyazovkin S., Burnham A.K., Criado J.M., PerezMaqueda L.A., Рopescu C., Sbirrazzuoli N. Thermochim. Acta. 2011. V. 520. P. 1-19. 